Research article

\title{
Association between alendronate, serum alkaline phosphatase level, and heterotopic ossification in individuals with spinal cord injury
}

\author{
Avraam Ploumis ${ }^{1,2}$, Jayne M. Donovan², Mobolaji 0. Olurinde², Dana M. Clark², \\ Jason C. Wü2, Douglas J. Sohn², Kevin C. O'Connor ${ }^{2}$ \\ ${ }^{1}$ Department of Physical Medicine and Rehabilitation, Spaulding Rehabilitation Hospital, Harvard Medical School, \\ Boston, MA, USA, ${ }^{2}$ Division of Orthopaedics \& Physical Medicine and Rehabilitation, Department of Surgery, \\ University of Ioannina, Ioannina, Greece
}

Context/objective: Only sparse evidence exists regarding the effectiveness of oral alendronate (ALN) in the prevention of heterotopic ossification $(\mathrm{HO})$ in patients with spinal cord injury $(\mathrm{SCl})$. The objective of this study is to investigate the protective effect of oral ALN intake on the appearance of $\mathrm{HO}$ in patients with SCl.

Study design: Retrospective database review.

Setting: A Spinal Cord Unit at a Rehabilitation Hospital.

Participants: Two hundred and ninety-nine patients with SCI during acute inpatient rehabilitation.

Interventions: Administration of oral ALN.

Outcome measures: The incidence of $\mathrm{HO}$ during rehabilitation was compared between patients with $\mathrm{SCl}$ receiving oral $\operatorname{ALN}(n=125)$ and patients with $\mathrm{SCl}$ not receiving oral ALN $(n=174)$. The association between $\mathrm{HO}$ and/or ALN intake with $\mathrm{HO}$ risk factors and biochemical markers of bone metabolism were also explored. Results: $\mathrm{HO}$ developed in 19 male patients (6.35\%), however there was no significant difference in the incidence of $\mathrm{HO}$ in patients receiving oral ALN or not. The mean odds ratio of not developing versus developing $\mathrm{HO}$ given ALN exposure was 0.8. Significant correlation was found between abnormal serum alkaline phosphatase (ALP) levels and $\mathrm{HO}$ appearance $(P<0.001)$ as well as normal serum ALP and ALN intake $(P<0.05)$.

Conclusion: Even though there was no direct prevention of $\mathrm{HO}$ in patients with $\mathrm{SCl}$ by oral ALN intake, abnormal serum ALP was found more frequently in patients with $\mathrm{HO}$ development and without oral ALN intake. This evidence could suggest that ALN may play a role in preventing $\mathrm{HO}$, especially in patients with acute $\mathrm{SCl}$ with increasing levels of serum ALP.

Keywords: Alendronate, Heterotopic ossification, Spinal cord injury

\section{Introduction}

Heterotopic ossification ( $\mathrm{HO})$ is the pathological formation of mature lamellar bone in muscle and soft tissues adjacent to joints. Although the mechanism for development of $\mathrm{HO}$ is not fully understood, it is thought to be associated with local inflammation in the soft tissues that induces transformation of mesenchymal stem cells into osteoblasts by prostaglandins. ${ }^{1}$ Osteoblasts produce tropocollagen and alkaline

Correspondence to: Avraam Ploumis, Division of Orthopaedics \& Physical Medicine and Rehabilitation, Department of Surgery, University of loannina, loannina 45110, Greece. Email: aploumis@cc.uoi.gr phosphatase (ALP). Tropocollagen polymerizes to form collagen fibers which are involved in the formation of the bone matrix, while ALP inactivates pyrophosphate allowing for calcium deposition and mineralization of the bone matrix which leads to development of ectopic bone. ${ }^{1}$

$\mathrm{HO}$ is a common complication following central nervous system disorders. The incidence of $\mathrm{HO}$ in patients with spinal cord injury (SCI) varies from 10 to $78 \%{ }^{1-3}$ It most frequently occurs $3-12$ weeks after $\mathrm{SCI}{ }^{2,4}$ is predominantly found in the $\operatorname{hip}^{5-7}$ and always occurs below the level of paralysis. ${ }^{2,6}$ Risk 
factors for the development of $\mathrm{HO}$ after SCI include complete lesions, thoracic injuries, pneumonia, spasticity, urinary tract infection (UTI), the presence of tracheostomy, pneumonia, and trauma. 8,9

HO typically presents with a non-specific inflammatory reaction including swelling, heat, pain (in cases with intact sensation), and erythema. ${ }^{3}$ As HO progresses, it can result in reduced range of motion and, eventually, joint ankylosis. $^{5,10}$ It can also cause skin breakdown and peripheral nerve entrapment. In individuals with SCI, HO may result in further functional impairments, significantly impede acute rehabilitation, and ultimately impair quality of life. ${ }^{5,10}$ Therefore, prevention is key.

Although there are several options for treatment of HO including radiotherapy, bisphosphonates (etidronate), and surgery, there are few current options that exist for the prevention of HO. A conservative prevention program should include patient education regarding the possible complication of $\mathrm{HO}$ and a consistent program to maintain joint range of motion. To date, only non-steroidal anti-inflammatory drugs (NSAIDs) have substantial evidence to support their use to prevent HO. It has been shown that, when given early, NSAIDs can reduce the development of HO. ${ }^{2,11}$ They are proposed to work by reducing inflammation and blocking prostaglandin synthesis. ${ }^{12}$ Nevertheless, this medication class may affect fracture healing and spinal fusion, therefore limiting its use in the acute SCI population. $^{13,14}$

Alendronate $(\mathrm{ALN})$ is a potent $\mathrm{N}$-containing second generation bisphosphonate. At our institution, ALN has been prescribed to individuals early after SCI to limit disuse osteoporosis. ALN is thought to inhibit bone resorption and additionally has a small effect on mineralization. $^{15,16}$ It has also empirically been observed to decrease the rate of formation of clinically significant HO, but evidence supporting the effectiveness of bisphosphonates in primary prevention of $\mathrm{HO}$ after SCI is still lacking. ${ }^{15,16}$ The purpose of our study was to further investigate the role of ALN in the prevention of HO after SCI.

\section{Material and methods}

This is a retrospective study of patients admitted with SCI (ASIA A, B, C, and D) at Spaulding Rehabilitation Hospital (SRH) from 2006 to 2012. ALN $70 \mathrm{mg}$ in a tablet form (by Tagipharma Company, a generic pharmaceutical supplier, South Beloit, IL, USA) was prescribed weekly in a number of patients when the patient was able to receive oral medications and could tolerate sitting position for at least one and half-hour. The medication was administered either as treatment for osteoporosis or as antiosteoporotic preventive measure in patients with AIS A, B, or C. Patients were included if they had full data available for at least 3 months from the time of their admission to the rehabilitation unit. Patients presenting with neuropathies (Guillain-Barré syndrome, multiple sclerosis, syndromes, etc.) or myopathies, without cord deficit or with non-acute SCI (more than 3 months from time of injury incident) were excluded.

Data collected included demographics (age, sex), date of injury, date of admission at SRH, duration of followup, type of injury (traumatic or non-traumatic SCI), level (cervical or thoracic-lumbar-sacral) and completeness (motor complete or not) of injury, concomitant traumatic brain injury (TBI) or not, spinal fusion or not, date of ALN start and duration, early or late (more than 3 months from injury) ALN start, known osteopenia or osteoporosis (by dual-energy X-ray absorptiometry (DEXA) measurement), NSAIDs intake, warfarin intake, antispasmodic medications intake, maximum abnormal laboratory findings of bone-muscle metabolism indices (values for serum ALP, serum creatine phosphokinase $\mathrm{CPK}$, serum parathyroid hormone $\mathrm{PTH}$ ). The normal laboratory values for ALP is $40-150 \mathrm{U} / 1$, for CPK 22-198 U/1, and for PTH 10-55 pg/ml.

Our primary outcome measure was documentation of $\mathrm{HO}$ in the medical record based on radiographic examinations (always plain X-rays done at our hospital, rarely triple phase bone scan as this was an offsite exam with increased radiation for the patient). Clinical notes and therapist reports mentioning joint stiffness-contractures were documented separately from $\mathrm{HO}$ incidence as contracture incidence without radiographic abnormality. Secondary outcome measures included time of $\mathrm{HO}$ appearance from the time of injury, joint affected (hip, knee, shoulder, elbow, spine, hand, ankle), and type of HO treatment (surgery-radiation-medications).

Statistical analysis was performed with SPSS version 10.0 (SPSS, Inc., Chicago, IL, USA). Descriptive statistics were used to present data. Numerical data were presented as mean \pm standard deviation (SD). Correlations between the appearance of $\mathrm{HO}$ and ALN intake or other parameters (demographic, clinical, laboratory) were calculated with $\chi^{2}$ test and Fisher's exact test. The Mantel-Haenszel $t$-test was used to estimate the odds ratio of developing versus not developing $\mathrm{HO}$ given ALN exposure. Differences of mean values of ALP were calculated with independent samples $t$-test (separate-variance $t$-tests for equality of means). All statistical tests were conducted at a 0.05 significance level (P-value). 


\section{Results}

From the initial file of 754 patients with SCI admitted to the rehabilitation hospital between 2006 and 2012, we initially included 570 patients (the rest were missing from the system or did not have all data needed to be included). Two hundred and ninety-nine patients with SCI who presented within 3 months from their deficit and with at least 3 months follow-up time were finally included in the study. The average follow-up time was $626.72 \pm 620.49$ days. The mean age of the patients was $42.7 \pm 18.36$ years while male subjects were 226 of total. Patients were admitted to the rehabilitation department an average of $21.31 \pm 17.16$ days following their injury. HO (with bone formation evident in radiographs) was found in $19(6.35 \%)$ patients, mostly hip joint (13 patients) with the remaining in the knee, shoulder, and elbow joint. Type of treatment until the last follow-up included NSAIDs in all cases, surgery in three $(15.8 \%)$ cases, and radiotherapy in two $(15.2 \%)$ cases. The diagnosis of $\mathrm{HO}$ was made in $290.1 \pm 379.5$ days from the initial injury. Contracture (defined as limitation of range of motion without radiographic evidence of osseous transformation) was reported in 26 patients $(8.7 \%)$, mainly in the ankle and the metacarpophalangea1-interphalangeal joints of the hand.

ALN was prescribed in 125 patients $(41.8 \%)$ for an average $267.2 \pm 405.09$ days or $38.17 \pm 57.89$ weeks with mean cumulative dosing of $2672 \pm 4050 \mathrm{mg}$. Seventy-one of those received the drug as early as 3 months from the SCI. Table 1 shows the characteristics of patients with and without ALN intake. Patients who received ALN were more frequently $(\mathrm{P}<0.05)$ males
Table 2 Odds ratio of not developing versus developing HO given ALN exposure

\begin{tabular}{lccc}
\hline & $\begin{array}{c}\text { Patients } \\
\text { with HO }\end{array}$ & $\begin{array}{c}\text { Patients } \\
\text { without HO }\end{array}$ & $\begin{array}{c}\text { Odds ratio (95\% } \\
\text { confidence interval) }\end{array}$ \\
\hline $\begin{array}{l}\text { Patients with } \\
\text { ALN intake }\end{array}$ & 7 & 118 & $0.8(0.3-2)$ \\
$\begin{array}{l}\text { Patients } \\
\text { without ALN } \\
\text { intake }\end{array}$ & 12 & 162 & \\
\begin{tabular}{l} 
Total \\
\hline
\end{tabular} & 19 & 280 & \\
\hline
\end{tabular}

who had traumatic, complete, cervical cord injuries, were not operated and were prescribed with antispasmodic medications. There was no significant correlation between the diagnosis of $\mathrm{HO}$ and oral ALN intake (Table 2). However, there were more patients receiving ALN who developed contractures $(\mathrm{P}<0.001)$.

The mean maximum serum ALP measurement was $171.29 \pm 169.69 \mathrm{U} / 1$. There was a significant difference $(\mathrm{P}<0.01)$ of mean serum ALP level between patients with $\mathrm{HO}(307.61 \pm 486.29)$ and patients without HO $(158.65 \pm 93.59)$. From the Fisher's exact test, significant correlations $(\mathrm{P}<0.05)$ were found between $\mathrm{HO}$ appearance and male sex as well as between $\mathrm{HO}$ appearance and serum ALP abnormality $(\mathrm{P}<0.001)$. Furthermore, ALN intake (125 patients, $41.8 \%$ ) and normal serum ALP (201 patients, $67.2 \%)$ were positively correlated $(\mathrm{P}<0.05)$.

No significant correlations $(\mathrm{P}>0.05)$ were found between the development of $\mathrm{HO}$ and age $<50$ years old, traumatic SCI, level of SCI, spinal surgical procedure, co-existence of TBI, the presence of osteoporosis or antispasmodic medications intake, and abnormal values of serum CPK or PTH.

Table 1 Characteristics of patients with SCI with and without ALN oral intake

\begin{tabular}{|c|c|c|c|}
\hline & $\begin{array}{l}174 \text { patients without } \\
\text { oral ALN intake }\end{array}$ & $\begin{array}{l}125 \text { patients with } \\
\text { oral ALN intake }\end{array}$ & P-value \\
\hline Age & $44.2(18)$ & $40.6(18.7)$ & $>0.05$ \\
\hline Time of ALN start (days from admission) & $21(18.6)$ & $21.8(15)$ & $>0.05$ \\
\hline Duration (in days) of ALN use & & $267.2(458)$ & $>0.05$ \\
\hline Max ALP serum level & $165.7(198.6)$ & $181.4(99.1)$ & $>0.05$ \\
\hline Male sex & $140(80.4)$ & $86(68.8)$ & $<0.05$ \\
\hline Traumatic SCl & $117(67.2)$ & $102(81.6)$ & $<0.01$ \\
\hline Cervical SCl & $77(44.2)$ & $79(63.2)$ & $<0.005$ \\
\hline Motor complete SCl & $64(36.8)$ & $89(71.2)$ & $<0.001$ \\
\hline Surgery for $\mathrm{SCl}$ & $45(25.9)$ & $19(15.2)$ & $<0.05$ \\
\hline TBI & $17(9.8)$ & $20(16)$ & $>0.05$ \\
\hline Osteoporosis & $4(2.3)$ & $7(5.6)$ & $>0.05$ \\
\hline Spasticity necessitating antispasmodic medications & $111(63.8)$ & $96(76.8)$ & $<0.05$ \\
\hline Anticoagulation (warfarin intake) & $24(13.8)$ & $21(16.8)$ & $>0.05$ \\
\hline Abnormal serum ALP & $49(28.2)$ & $49(39.2)$ & $<0.05$ \\
\hline Abnormal serum creatinophosphokinase & $7(4)$ & $11(8.8)$ & $>0.05$ \\
\hline Abnormal serum parathormone & $3(1.7)$ & $4(3.2)$ & $>0.05$ \\
\hline Contracture development & $7(4)$ & $19(15.2)$ & $<0.001$ \\
\hline
\end{tabular}

Values are presented in mean (SD) for continuous variables (top four variables) and $n$ (\%) for categorical variables (bottom variables).

$\mathrm{P}$-values in bold indicate statistical significance. 


\section{Discussion}

Pharmacological therapeutic options available for management of $\mathrm{HO}^{17}$ include NSAIDs, ${ }^{2,12}$ warfarin, and bisphosphonates. Specifically, the NSAID, indomethacin, ${ }^{2}$ and rofecoxib, ${ }^{11}$ delay and/or prevent development of HO after SCI presumably by inhibiting prostaglandins and inflammatory mediators required for transformation of mesenchymal cell into osteoblasts. Notably, NSAID use in acute SCI may affect fracture healing and spinal fusion, thereby limiting its widespread use. Even though etidronate is the "state of the art"-Food and Drug Administration approved bisphosphonate for the treatment and prevention of $\mathrm{HO}$, its antiosteoporotic effect is lower than ALNs since etidronate's main effect is the inhibition of bone mineralization and has minimal effect on bone matrix formation. ${ }^{15,16}$ In our retrospective study of patients with SCI exploring risk factors for $\mathrm{HO}$ development and possible inhibitory effect of ALN, there was no statistically significant prevention of $\mathrm{HO}$ in patients receiving oral ALN as antiosteoporotic treatment. However, there seems to be an indirect correlation between oral ALN and HO prevention in patients with SCI given the finding that patients with $\mathrm{HO}$ had abnormal serum ALP levels and oral ALN intake was strongly correlated with normal serum ALP levels.

The high incidence of clinically significant $\mathrm{HO}$ in patients with SCI is widely reported. ${ }^{10,18}$ Risk factors for HO formation in patients with SCI have been established as, spasticity, pressure ulcers, completeness of SCI, thoracic lesions, pneumonia, UTIs, and the presence of tracheostomy. ${ }^{9,18}$ Risk factors for HO recurrence are considered cognition deficits, spasticity, and massive HO. ${ }^{19}$ In our retrospective study, only male sex was confirmed as risk factor for $\mathrm{HO}$ formation and there was no statistical significant correlation with age, spasticity, level of SCI, or motor complete injuries.

There are no specific symptoms or diagnostic tests to predict the population of patients with SCI that will develop HO. The typical clinical presentation is pain, warmth, erythema, local swelling, decreased range of motion, and increased spasticity. Sometimes patients with SCI do not have pain. Therefore, skeletal biomarkers could help early HO diagnosis. ${ }^{16,19}$ Elevated levels of serum ALP, ${ }^{18,20} \mathrm{CPK},{ }^{20} \mathrm{C}$-reactive protein, ${ }^{21}$ erythrocyte sedimentation rate, ${ }^{18,21}$ and prostaglandin $\mathrm{E} 2^{7}$ are associated with $\mathrm{HO}$ after SCI. Elevated levels of serum CPK but not ALP is correlated with the severity of HO. ${ }^{20}$ Some researchers support that stabilization of ALP is an indicator of HO maturation, ${ }^{19}$ while others do not think the same. ${ }^{22}$ However, these biomarkers are non-specific. Except from HO formation, other osseous causes of serum ALP elevation in acute SCI are fracture or bone surgery. Non-osseous causes of ALP elevation are hepatic, renal, gastrointestinal, metabolic, and general skeletal disorders. ${ }^{23,24}$ In our study, it was confirmed that abnormal serum ALP was positively correlated to HO formation.

An observational retrospective study suggested that warfarin is associated with a reduction in the incidence of $\mathrm{HO}$ after SCI. ${ }^{4}$ Warfarin inhibits vitamin K-dependent glutamate carboxylation which is required for osteocalcin protein that is needed for bone matrix production. However, despite the evidence suggesting that warfarin may be an effective prophylaxis against $\mathrm{HO},{ }^{4}$ in some patients the risk of hemorrhage could outweigh its potential benefit, therefore limiting its use. In our series of 299 patients with SCI, the preventive effect of warfarin on $\mathrm{HO}$ formation was not seen.

Bisphosphonates inhibit the enzyme, farnesyl pyrophosphate synthase, which prevents mineralization of the bone matrix. ${ }^{25}$ Etidronate, a bisphosphonate, has been shown to delay development and progression of HO in its early stages. ${ }^{15,26-28}$ Surgical excision followed by administration of etidronate ${ }^{29,30}$ or pamidronate ${ }^{6}$ prevents the recurrence of HO. Stover et al. ${ }^{28,29}$ in 1976 concluded that disodium etidronate offered protection of $\mathrm{HO}$ recurrence in four patients operated for $\mathrm{HO}$ resection. Similarly, Banovac, ${ }^{15}$ in a $1.5-6$ years followup study of 40 patients with SCI who received intravenous etidronate for 3 days and continued with oral etidronate for 6 months totally, confirmed the absence of high-grade $\mathrm{HO}$ in these patients and interpreted it as the beneficial effect of etidronate compared. Aminobiphosphonates, such as ALN and risedronate, offer more antiresorptive osseous effect and minimal inhibition of mineralization. Animal studies though have confirmed that ALN mainly acts as osteoclast inhibitor rather than bone formation cell activator. ${ }^{31}$ For this reason, aminobiphosphonates are more appropriate for the prevention and treatment of osteoporosis. ${ }^{32}$ There are sparse reports though that ALN also has a beneficial effect in $\mathrm{HO}$ prevention. ${ }^{33}$ In this study, we explored the additional benefit of $\mathrm{HO}$ prevention in patients with SCI receiving oral ALN for osteoporosis prevention. However, no statistically significant correlation was found.

ALN has been shown to improve bone mineral density in hip or spine in elderly women. This has been associated with the reduction of bone turnover biochemical markers such as serum ALP. ${ }^{34,35}$ In addition, Braga de Castro Machado et al. ${ }^{36}$ supported that 
biochemical markers are a better way to monitor treatment with ALN than dual energy X-ray absorptiometry (DEXA) values. In our study, oral ALN intake by SCI patients was correlated with normal serum ALP and this may be indirectly associated with HO prevention. Also, since ALN intake was correlated with the appearance of joint contractures, we cannot be sure if these cases would have proceeded to HO if ALN was not prescribed and that ALN could prevent progression to severe HO-joint ankylosis.

A limitation to our study is the retrospective design with non-consistent start time or duration of ALN intake and different characteristics between the nonALN and ALN patient groups. However, the results are valid as level III evidence. Since triple phase bone scan as gold standard for the diagnosis of HO was not used universally, there is a chance that we may have missed cases of subclinical or early HO. However, these cases were sparse, if any, based on the high index of suspicion of the physicians and therapists during their multiple and frequent patient evaluations. Furthermore, since the majority of patients in our population were of male sex, firm conclusions on the sex predilection of HO in patients with SCI cannot be drawn. Prospective randomized trials with controlled patient selection criteria as well as multicenter studies on the prevention of $\mathrm{HO}$ by oral ALN intake with bonespecific ALP measurement are warranted.

According to the results above, even though ALN intake does not seem to have direct preventive action for $\mathrm{HO}$, it correlates with normal ALP levels and may indirectly influence HO. Patients with acute SCI with HO risk factors should have regular serum ALP measurements and when increasing ALP levels are found, ALN could be prescribed, if not contraindicated, for $\mathrm{HO}$ prevention.

\section{Disclaimer statements}

Contributors AP: Data collection, statistical analysis, manuscript writing. JD: Data collection and manuscript writing. MO: Data collection and manuscript writing. DC: Data collection and manuscript writing. JW: Data collection and manuscript writing. DS: Data collection. KOC: Review of manuscript.

\section{Conflicts of interest None.}

Ethics approval None.

Funding None.

\section{References}

1 van Kuijk AA, Geurts AC, van Kuppevelt HJ. Neurogenic heterotopic ossification in spinal cord injury. Spinal Cord 2002;40(7): $313-26$.
2 Banovac K, Williams JM, Patrick LD, Haniff YM. Prevention of heterotopic ossification after spinal cord injury with indomethacin. Spinal Cord 2001;39(7):370-4.

3 Vanden Bossche L, Vanderstraeten G. Heterotopic ossification: a review. J Rehabil Med 2005;37(3):129-36.

4 Buschbacher R, McKinley W, Buschbacher L, Devaney CW, Coplin B. Warfarin in prevention of heterotopic ossification. Am J Phys Med Rehabil 1992;71(2):86-91.

5 Hardy AG, Dickson JW. Pathological ossification in traumatic paraplegia. J Bone Joint Surg Br 1963;45-B(1):76-87.

6 Schuetz P, Mueller B, Christ-Crain M, Dick W, Haas H. Aminobisphosphonates in heterotopic ossification: first experience in five consecutive cases. Spinal Cord 2005;43(10):604-10.

7 Schurch B, Capaul M, Vallotton MB, Rossier AB. Prostaglandin e2 measurements: their value in the early diagnosis of heterotopic ossification in spinal cord injury patients. Arch Phys Med Rehabil 1997;78(7):687-91.

8 Coelho CV, Beraldo PS. Risk factors of heterotopic ossification in traumatic spinal cord injury. Arq Neuropsiquiatr 2009;67(2B): $382-7$.

9 Citak M, Suero EM, Backhaus M, Aach M, Godry H, Meindl R, et al. Risk factors for heterotopic ossification in patients with spinal cord injury: a case-control study of 264 patients. Spine (Phila Pa 1976) 1976;37(23):1953-7.

10 Garland DE, Orwin JF. Resection of heterotopic ossification in patients with spinal cord injuries. Clin Orthop Relat Res 1989; 67(8):169-76.

11 Banovac K, Sherman AL, Estores IM, Banovac F. Prevention and treatment of heterotopic ossification after spinal cord injury. $\mathrm{J}$ Spinal Cord Med 2004;27(4):376-82.

12 Banovac K, Williams JM, Patrick LD, Levi A. Prevention of heterotopic ossification after spinal cord injury with cox-2 selective inhibitor (rofecoxib). Spinal Cord 2004;42(12):707-10.

13 Kurmis AP, Kurmis TP, O'Brien JX, Dalen T. The effect of nonsteroidal anti-inflammatory drug administration on acute phase fracture-healing: a review. J Bone Joint Surg Am 2012;94(9): 815-23.

14 Pountos I, Georgouli T, Calori GM, Giannoudis PV. Do nonsteroidal anti-inflammatory drugs affect bone healing? A critical analysis. Scientific World Journal 2012 (article id 606404):1-14.

15 Banovac K. The effect of etidronate on late development of heterotopic ossification after spinal cord injury. J Spinal Cord Med 2000; 23(1):40-4.

16 Garland DE, Alday B, Venos KG, Vogt JC. Diphosphonate treatment for heterotopic ossification in spinal cord injury patients. Clin Orthop Relat Res 1983;176:197-200.

17 Teasell RW, Mehta S, Aubut JL, Ashe MC, Sequeira K, Macaluso $\mathrm{S}$, et al. A systematic review of the therapeutic interventions for heterotopic ossification after spinal cord injury. Spinal Cord 2010; 48(7):512-21.

18 Wittenberg RH, Peschke U, Botel U. Heterotopic ossification after spinal cord injury. Epidemiology and risk factors. J Bone Joint Surg Br 1992;74(2):215-8.

19 Garland DE, Hanscom DA, Keenan MA, Smith C, Moore T. Resection of heterotopic ossification in the adult with head trauma. J Bone Joint Surg Am 1985;67(8):1261-9.

20 Singh RS, Craig MC, Katholi CR, Jackson AB, Mountz JM. The predictive value of creatine phosphokinase and alkaline phosphatase in identification of heterotopic ossification in patients after spinal cord injury. Arch Phys Med Rehabil 2003;84(11): 1584-8.

21 Estrores IM, Harrington A, Banovac K. C-reactive protein and erythrocyte sedimentation rate in patients with heterotopic ossification after spinal cord injury. J Spinal Cord Med 2004; 27(5):434-7.

22 Kim SW, Charter RA, Chai CJ, Kim SK, Kim ES. Serum alkaline phosphatase and inorganic phosphorus values in spinal cord injury patients with heterotopic ossification. Paraplegia 1990; 28(7):441-7.

23 Bernard GW. Ultrastructural localization of alkaline phosphatase in initial intramembranous osteogenesis. Clin Orthop Relat Res 1978;135:218-25.

24 Siddique A, Kowdley KV. Approach to a patient with elevated serum alkaline phosphatase. Clin Liver Dis 2012;16(2):199-229. 
25 Licata AA. Discovery, clinical development, and therapeutic uses of bisphosphonates. Ann Pharmacother 2005;39(4):668-77.

26 Banovac K, Gonzalez F. Evaluation and management of heterotopic ossification in patients with spinal cord injury. Spinal Cord 1997;35(3):158-62.

27 Banovac K, Gonzalez F, Renfree KJ. Treatment of heterotopic ossification after spinal cord injury. J Spinal Cord Med 1997; 20(1):60-5.

28 Stover SL, Hahn HR, Miller JM III. Disodium etidronate in the prevention of heterotopic ossification following spinal cord injury (preliminary report). Paraplegia 1976;14(2):146-56.

29 Stover SL, Niemann KM, Miller JM III. Disodium etidronate in the prevention of postoperative recurrence of heterotopic ossification in spinal-cord injury patients. J Bone Joint Surg Am 1976; 58(5):683-8.

30 Subbarao JV, Nemchausky BA, Gratzer M. Resection of heterotopic ossification and didronel therapy-regaining wheelchair independence in the spinal cord injured patient. J Am Paraplegia Soc $1987 ; 10(1): 3-7$.
31 Yaffe A, Kollerman R, Bahar H, Binderman I. The influence of alendronate on bone formation and resorption in a rat ectopic bone development model. J Periodontol 2003;74(1):44-50.

32 Moran de Brito CM, Battistella LR, Saito ET, Sakamoto H. Effect of alendronate on bone mineral density in spinal cord injury patients: a pilot study. Spinal Cord 2005;43(6):341-8.

33 Ben Hamida KS, Hajri R, Kedadi H, Bouhaouala H, Salah MH, Mestiri A, et al. Myositis ossificans circumscripta of the knee improved by alendronate. Joint Bone Spine 2004;71(2):144-6.

34 Greenspan SL, Parker RA, Ferguson L, Rosen HN, MaitlandRamsey L, Karpf DB. Early changes in biochemical markers of bone turnover predict the long-term response to alendronate therapy in representative elderly women: a randomized clinical trial. J Bone Miner Res 1998;13(9):1431-8.

35 Zehnder Y, Risi S, Michel D, Knecht H, Perrelet R, Kraenzlin M, et al. Prevention of bone loss in paraplegics over 2 years with alendronate. J Bone Miner Res 2004;19(7):1067-74.

36 Braga de Castro Machado A, Hannon R, Eastell R. Monitoring alendronate therapy for osteoporosis. J Bone Miner Res 1999;14(4):602-8. 